ARTÍCULO

\title{
TOPÓNIMOS EN LA COSTA YUCATÁN-BELICE VARIACIÓN DEL NOMBRE EN ALGUNOS CAYOS E ISLOTES
}

\author{
PLACE NAMES ON THE YUCATAN-BELIZE COAST \\ VARIATION OF THE NAME OF SOME KEYS AND ISLETS
}

\author{
Martín Ramos DíAz \\ Universidad de Quintana Roo \\ Departamento de Humanidades \\ martinramosdiaz@gmail.com
}

Resumen

La historia de los topónimos en la costa Yucatán-Belice es una investigación por hacerse. Los datos cartográficos, etnográficos y lingüísticos aportados por distintas fuentes históricas son un primer censo de la variación toponímica en el área. Desconocemos la toponimia amerindia de docenas de islotes y cayos vecinos al arrecife mesoamericano. Del análisis de los mapas históricos disponibles del Caribe se desprende un registro de cuándo fueron sustituidos los sustantivos geográficos amerindios por una toponimia hispana, inglesa, francesa u holandesa. La siguiente investigación sobre la variación de nombres geográficos en una región costera es un recorrido por la historia de la formación de topónimos en la orilla marítima del Caribe mexicano y en la parte norte de Belice. A partir del análisis de mapas novohispanos y decimonónicos, se propone una inicial clasificación de topónimos de la región en seis grupos.

Palabras clave: formación de topónimos, variación de topónimos, costa Yucatán-Belice.

\begin{abstract}
The history of toponymy of the Yucatan-Belize coast is an investigation to be done. The cartographic, ethnographic and linguistic data provided by different historical sources account for the earlier records of the toponymy variation of the area. The Amerindian names of dozens of islets and cays neighboring the Mesoamerican Reef remain unknown. The analysis of the available historical maps of the Caribbean region makes known the time period of replacement of Amerindian toponymy by Hispanic, English, French or Dutch place names. The present work is an inquiry into the history of place-name labeling on the maritime shore of the Mexican Caribbean and the northern part of Belize. Based on the analysis of Novohispanic and nineteenth-century maps, a preliminary classification of toponymy of the region into six groups is proposed.
\end{abstract}

Keywords: Place-name labeling, Place-name variation, Yucatan-Belize coast.

Información del artículo

Recibido: 22 de julio de 2019.

Aceptado: 27 de septiembre de 2019.

DOI: 10.22201/iih.24485004e.2019.58.70255 


\section{INTRODUCCIÓN}

Los primeros faros metálicos llegaron a la costa oriental de Yucatán a finales del siglo XIX, en los años de auge económico del gobierno de Porfirio Díaz y como parte de los preparativos para la pacificación de los mayas rebeldes al final de la guerra de castas de Yucatán (1847-1901). Antes de las señales luminosas de los faros, los navegantes de la costa mexicana tenían una guía fiable en el contenido descriptivo, el significado o el aviso de los topónimos sembrados en las cartas de navegación. Aunque la toponimia del cayerío menor ha sido poco relevante en los estudios de la historia regional -es decir, el nombre dado a pequeñas islas arenosas, a canales estrechos, a puntas de tierra anegables, a porciones de arrecife-, ese conjunto de sitios y su nombre escrito en los mapas antiguos y modernos fue durante siglos la única guía para el cabotaje en la costa del Caribe mexicano.

El presente trabajo sobre topónimos costeros recupera y organiza información cartográfica y documental sobre algunos casos en el cayerío de la costa Yucatán-Belice. En un trayecto que en el pasado las pequeñas embarcaciones hicieron cientos de veces, sin abandonar la costa y procurando navegar en el mar interior de la barrera del arrecife, se identifican topónimos con una extensa historia en la variación de su nombre. Con la ayuda de las fuentes históricas existentes y con los datos de mapas novohispanos y modernos es posible organizar la toponimia costera del área en: advertencias de naufragio (grupo 1), nombres de colonos (grupo 2), peculiaridades edáficas y zoográficas (grupo 3), traducciones enredadas (grupo 4), pasados étnicos (grupo 5) y nombres llanos (grupo 6) de la vida cotidiana de los navegantes.

Advertencias de naufragio (grupo 1)

Los mapas coloniales nombraban "Quitasueño" a la sección de arrecife que hoy conocemos como Banco Chinchorro. El nombre constituía una especie de aviso para mantener alerta a la tripulación de las embarcaciones mientras cruzaban ciertas áreas próximas al arrecife. Más sutil para el entendimiento contemporáneo, pero temible para el marinero novohispano y decimonónico, el arrecife "Alacranes" es sinécdoque que advierte de filosos salientes de roca que acechan el paso de los barcos para "picarlos", dañarles el casco o la quilla y hacerlos naufragar. 
Nombres de colonos (grupo 2)

Taladores de maderas preciosas y de árboles tintóreos, individuos que arrendaron en los siglos XVIII y XIX grandes porciones de selva costera, muchas veces meros ocupantes de terrenos abandonados en la faja marítima, los mismos que terminaron por dar su nombre a los lugares que ocuparon. Como Tom Laco o Tom Jacob, un talador de la colonia inglesa (el actual Belice), que dejó su nombre a una pequeña isla en la Bahía de Chetumal en la que solía acampar para extraer madera: la isla de Tamalcab. En la sección norte de Cayo Ambergris, otro colono inglés llamado Basil Jones dejó tres sitios con su nombre a su paso por la colonia inglesa. Transformado por las equivocaciones de la escritura española, más no de lo que el oído hispano creía escuchar: Basil Jones derivó en Bercellón, punta Bercellón, rancho Bercellón y un canal entre el arrecife, frente a los terrenos que arrendó: canal Bercellón.

Peculiaridades edáficas y zoográficas (grupo 3)

La toponimia edáfica y zoográfica de la faja costera Yucatán-Belice —con más de dos centenares de cayos, bajos e isletas-conserva en sus sustantivos una historia vegetal, animal y geológica. Numerosos topónimos de los documentos de la Expedición yucateca a Cayo Cosina de 1798 (EYCC-1798, en adelante) evocan una flora, una fauna y una geología cambiante. Los nombres de cayos e isletas, de canales entre el arrecife para acceder desde el mar interior al mar abierto, de bajos peligrosos que se debían evitar en la ruta de navegación, de puntas de tierra y de pequeñas islas que aparecían y desaparecían según la temporada de año, muestran una orilla caribeña laberíntica para la navegación de cabotaje. El conjunto de esos sustantivos geográficos son a la vez el registro de flora y fauna engañosamente parecida entre una y otra isla.

\section{Traducciones enredadas (grupo 4)}

Puntas rocosas salientes del mar, promontorios de piedra, tamaño de las isletas y color de las aguas en canales y manglares fueron señales de ruta para los marinos del cabotaje novohispano y decimonónico en las cercanías 
del arrecife mesoamericano. Punta Piedras, Cayo Largo o isletas con vegetación baja, como Cayo Sabana, explican su topónimo por sí solas. Pero con Cay Chapel las traducciones de la cartografía inglesa y española se enredan.

Pasados étnicos (grupo 5)

La toponimia de la costa Yucatán-Belice señala, además de nombres de origen maya, rasgos étnicos de los cortadores de madera y de árboles tintóreos, como en Cayo Negro.

Nombres llanos (grupo 6)

La toponimia novohispana y decimonónica de la orilla del mar Caribe dibuja una costa Yucatán-Belice en la que encallan o se pierden con facilidad las naves. Algunos atajos para pequeñas embarcaciones (Boca Chica) parecen salir de la inocuidad y de los sucesos cotidianos. Como las referencias para orientar el camino (Punta Piedras) y para recordar los sitios donde la picadura de los abundantes mosquitos produce fiebre (Punta Calentura).

Las seis secciones en las que organizamos la toponimia costera analizada son también un balance de la pérdida. Debe esperar por ahora la elaboración de un inventario de los topónimos amerindios en la costa Yucatán-Belice la falta de fuentes primarias no lo permite. Sin embargo, no es información menor lo que la narrativa histórica y la cartografía colonial y decimonónica ofrecen para el estudio de los topónimos en la región. Un viejo acento, pátina de cadencia léxica y de dicciones de otra época, vibra en los sustantivos geográficos costeros del cayerío menor que aquí recorremos.

\section{Grupo 1. AdVERtencias de naufragio: \\ Quitasueño y AlaCRANES}

Como se detalla párrafos adelante, los mapas históricos muestran las distintas grafías de Quitasueño escritas sobre la ubicación del Banco Chinchorro, lugar al que las centurias encimaron otros sustantivos geográficos. Al infortunio de las embarcaciones que por descuido o mal tiempo desbarataron la quilla en un arrecife $-\mathrm{y}$ a la larga agonía de los náufragos 
abandonados en las isletas, cayos y salientes- se debe el nombre del Bajo Alacranes. Como hallarse casualmente con un alacrán venenoso en las praderas líquidas del mar Caribe. Alacranes es metonimia del peligro a que estaban expuestos los navegantes en las costas del Caribe: la de ser arrojados por las corrientes del mar o por el descuido de la tripulación sobre el filo de las rocas salientes del mar. Ser "mordido" o "picado" por los arrecifes en el casco del barco, como ser atacado por "alacranes". La inexorable muerte que llega con la toxina de la picadura del animal es el equivalente a la sed, el hambre y la insolación de la que lentamente morirían los náufragos en las isletas, después del naufragio por encalladura en el arrecife.

\section{Quitasueño, actualmente Banco Chinchorro}

Quitasueño, El Triángulo, Triángulos de Norte, Chinchorro y Cayo Grande son cinco topónimos para un mismo lugar. La media decena de sustantivos geográficos se usó entre el siglo XVI y mediados del siglo XIX, como se deduce de los mapas históricos. En los siglos XVI y XVII esa área aparece en la cartografía marítima con un nombre que resume las preocupaciones de los capitanes que cruzaban entre bajos y arrecifes: Quitasueño. Por un plano publicado por Herrera y Tordesillas en 1601 cotejamos que el lugar fue también conocido como "El Triángulo". ${ }^{1}$ Unas notas de Charles Darwin mencionan un arrecife llamado Triángulos de Norte, entre las islas Turneffe y Cozumel. ${ }^{2}$ Y luego en el siglo Xıx se agregó un nombre más al área: Cayo Grande.

Quitasueño predominó durante los siglos XVI, XVII y parte del XVIII para designar el área del actual Banco Chinchorro. En los mapas del siglo XVI y XVII consultados, se registran las siguientes variaciones para Quitasueño: “Quitasueno”, mapa de 1536-1538 de Alonso Álvarez de Pineda; ${ }^{3}$

${ }^{1}$ Michel Antochiw y Alain Breton, Catálogo cartográfico de Belice (1511-1880). Cartographic Catalog of Belize (1511-1880), San José (Costa Rica)/México, Bureau Régional de Coopération en Amérique Centrale/Centre d'Études Mexicaines et Centraméricaines, 1992, p. 69 , fig. 4.

${ }^{2}$ Charles Darwin, The Works of Charles Darwin. Volume 7. The Geology of the Voyage of the H. M. S. Beagle. Part I: Structure and Distribution of Coral Reefs, New York, New York University Press, 1986, p. 182.

${ }^{3}$ Antochiw y Breton, Catálogo cartográfico de Belice..., p. 69, fig. 3. 
"Quitazuenho", mapa de 1542 de Jean Rotz; “Quitasueño”, mapa de 1634 de Guillermo Blaeu; "Quitazueno", mapa de 1675 de Arent Roggeveen y Pieter Goos;" "Quitazuenho I", mapa de 1693 de Vincenzo Maria Coronelli;, “Quita Sueño”, mapa de 1703 de Guillaume de l'Isle; ; “Quita Zuno”, mapa de 1706 de Henry Popple; "I. Quitasueno", mapa de 1702 de Nicolás de Fer; ${ }^{10}$ "Quita el Sueño", mapa de 1755 de Juan de la Cruz y Tomás López. ${ }^{11}$

En un mapa de 1601, Herrera y Tordesillas deslizó otro nombre: "El Triángulo”. ${ }^{12}$ En la cartografía española el nombre quedó casi en el olvido, no así para los mapas ingleses de finales del siglo xviII que sumaron ambos nombres: "Chinchorro or North Triangles", plano de 1771 del capitán Joseph Smith Speer; ${ }^{13}$ "el Chinchorro or the Northern Triangles", plano de 1782 de Robert y William Hodgson. ${ }^{14}$ El cartógrafo español Juan José de León, en su mapa de 1785 optó por señalar dos lugares distintos del mismo banco de arrecife: "Chinchorro-Triángulo del Norte". ${ }^{15}$

Al finalizar el siglo XVIII, "Northern Triangles" era el topónimo para Chinchorro en los mapas ingleses, como se puede verificar en el plano de 1779 de William James, ${ }^{16}$ en el plano West Indies de $1806^{17}$ y en la referencia de Charles Darwin sobre arrecifes y formaciones coralinas antes indicada.

El actual topónimo "Chinchorro" es un sustantivo asignado a mediados del siglo xviII, en el mismo modo en que a mediados del siglo xix le asignaron "Cayo Grande". ${ }^{18}$ Las variaciones encontradas en los mapas marinos para la escritura de Chinchorro son las siguientes: "El Chinchorro", plano

${ }^{4}$ Michel Antochiw, Historia cartográfica de la península de Yucatán, México, Instituto Politécnico Nacional, Centro de Investigación y Estudios Avanzados/Gobierno del Estado de Campeche/Grupo Tribasa, 1994, desplegado Iv, entre p. 144-145.

${ }^{5}$ Antochiw, Historia cartográfica..., p. 162.

${ }^{6}$ Antochiw, Historia cartográfica..., p. 208-209, lámina 20.

${ }^{7}$ Antochiw, Historia cartográfica..., p. 167.

${ }^{8}$ Antochiw, Historia cartográfica..., p. 169.

9 Antochiw, Historia cartográfica..., p. 197.

${ }^{10}$ Antochiw, Historia cartográfica..., p. 168.

${ }^{11}$ Antochiw, Historia cartográfica..., p. 186.

12 Antochiw y Breton, Catálogo cartográfico de Belice..., p. 69, fig. 4.

${ }^{13}$ Antochiw y Breton, Catálogo cartográfico de Belice..., p. 81 y 138.

${ }^{14}$ Antochiw, Historia cartográfica..., p. 204.

15 Antochiw y Breton, Catálogo cartográfico de Belice..., p. 89 y 148, fig. xxxv, n. 56.

${ }^{16}$ Antochiw y Breton, Catálogo cartográfico de Belice..., p. 85 y 142, fig. xxIx, n. 49.

17 Antochiw, Historia cartográfica..., p. 205.

${ }^{18}$ Antochiw y Breton, Catálogo cartográfico de Belice..., p. 107 y 188, fig. LXXII, n. 100. 
de 1764 de Juan de Dios González;19 "Bo. de Chinchorro", Carta esférica del Seno Mexicano de 1765; ${ }^{20}$ "Chinchorro", plano de 1780 de Rigobert Bonne. ${ }^{21}$

Pero de los cinco sustantivos geográficos con los que la historia cartográfica ha conocido este sector del arrecife mesoamericano Quitasueño es el más evocador, quizá por ello ese antiguo nombre figura aún en otros rumbos peligrosos de la costa. En resumen: Chinchorro fue Quitasueño, El Triángulo, Triángulos del Norte y Cayo Grande. Y actualmente su nombre oficial es Reserva de la Biósfera Banco Chinchorro. Como topónimo de la cartografía moderna, Chinchorro comenzó a figurar en los planos de la costa oriental de Yucatán a partir de mediados del siglo XVIII, como ya hemos dejado asentado.

\section{Alacranes, la metonimia QUe ADVierte}

El cronista Gonzalo Fernández de Oviedo es la fuente hispana más antigua que recoge los detalles sobre el topónimo Alacranes:

Llámanse Alacranes porque este animal alacrán es muy enconado e de grand dolor su venino (el cual por otro nombre es dicho escorpión), e por ser tan malo e peligroso, se dió este nombre de Alacrán o Alacranes a las isletas que tengo dicho, de quien aquí se tracta, porque a los que por allí aportan e dan en ellas, las hacen morir dolorosamente. ${ }^{22}$

El relato del naufragio de un barco español en 1524 ilustra la metonimia de Alacranes. Alonso Zuazo, un pasajero del galeón encallado en aquel lugar, sobrevivió refugiándose en una isleta de donde meses después fue rescatado. De sus sufrimientos y miserias en aquellos cayeríos, sobrevivió bebiendo sangre de tortuga. Zuazo guardó un recuerdo duradero de Alacranes, recogido en las crónicas de Fernández de Oviedo. ${ }^{23}$ Gonzalo Guerrero y Jerónimo de Aguilar conocieron desde antes la agonía de naufragar en Alacranes y, como Alonso de Zuazo, sobrevivieron para narrarlo. Bernal

${ }^{19}$ Antochiw, Historia cartográfica..., p. 274.

${ }^{20}$ Antochiw, Historia cartográfica..., desplegado viı, entre p. 272 y 273.

${ }^{21}$ Antochiw, Historia cartográfica..., p. 177.

${ }^{22}$ Gonzalo Fernández de Oviedo, Historia general y natural de las Indias, 5 v., Madrid, Atlas, 1992 (Biblioteca de Autores Españoles, 118), v. v, p. 343.

${ }^{23}$ Fernández de Oviedo Historia general y natural..., v. v, p. 322-356. 
Díaz del Castillo registra la versión contada por el propio Jerónimo de Aguilar sobre su paso por Alacranes. ${ }^{24}$

Menos conocidos para el mundo contemporáneo son los datos del capitán Ciriaco Ceballos, quien a principios del siglo XIX aconsejó a los capitanes de las embarcaciones "huir de las proximidades del sitio". Alacrán o Alacranes es un bajo que se extiende de norte a sur 14 millas y 11 de este a oeste, informa el capitán. En el área - describe Ceballos- se hallan tres islas llamadas de Pérez, Chica y de Pájaros, con varios "placeres" y arrecifes que sobresalen de la superficie del agua. A su parte meridional se forma un puerto entre los arrecifes, muy abrigado y seguro: "este puerto sólo es frecuentado de los campechanos que van a hacer grasa de los muchos pescados que hay en él". ${ }^{25}$

El nombre actual del sitio es Parque Nacional Arrecife Alacranes. Como se puede corroborar por los mapas y testimonios de navegantes como Ceballos, desde el siglo Xvi el nombre del lugar, más que un zoónimo de la toponimia costera, es un aviso de encalladura por arrecifes ocultos o visibles.

\section{GRUPO 2. NOMBRES DE COLONOS: TOM LACO Y BASIL JONES}

Además del azar y del capricho, algunos topónimos son producto de errores y transformaciones en la escritura. Un claro ejemplo es la Isla de Tris. La isla "Trs" figuraba en los mapas españoles como abreviatura de la isla de "Términos". Pero ese nombre abreviado se trasladó a los mapas ingleses del siglo XVII como isla de Tris. ${ }^{26}$ En ese mismo modo, de equívocos en la escritura o en la pronunciación de palabras en una frontera de la Corona española y de la Corona inglesa, una pequeña isla en la bahía de Chetumal rentada u ocupada por un súbdito inglés, un tal Tom Laco o Tom Jacob, se convirtió al paso del tiempo en "Tamalcab", isla de Tamalcab. No nos debería sorprender este modo de nacer de los topónimos: el ejemplo más

${ }^{24}$ Bernal Díaz del Castillo, Historia verdadera de la conquista de la Nueva España, 2 v., México, Porrúa, 1977, v. I, p. 103.

${ }^{25}$ Derrotero de las islas antiguas, de las costas de tierra firme y de las del seno megicano, corregido y aumentado con un apéndice sobre las corrientes del océano Atlántico, Bogotá, Dirección de Hidrografía, 1826, p. 436.

${ }^{26}$ William Dampier, Dos viajes a Campeche. Con el facsímil de la edición inglesa de 1705, México, Miguel Ángel Porrúa, 2004, p. XviII. 
conocido en la región de un sustantivo geográfico originado así es Belice. Calderón Quijano estudió detalladamente la documentación que permite seguir el proceso de evolución de lo que originalmente fue Wallace, "nombre del bucanero que arribó al Río Viejo en la segunda mitad del siglo XVII" para convertirse en Belice. ${ }^{27}$

El equívoco lingüístico fue común en las fronteras caribeñas de la Corona española e inglesa. Historias parecidas sobre la formación de sustantivos geográficos se repiten con frecuencia en la toponimia costera. El nombre del colono inglés Basil Jones pasó a ser "Bercellon", quebrado de Bercellón. Un quebrado es un canal entre el arrecife, en este caso el quebrado se ubica frente a la propiedad de Basil Jones.

Ambos casos, Bercellón y Tamalcab, ilustran el tránsito de nombre de personas a topónimos costeros. Y derriban la generalizada creencia de que Tamalcab es voz maya o que Barcellón tiene su origen en los corsarios franceses que asolaron la costa Yucatán-Belice. Ambos casos recorrieron un camino similar al explicado en el estudio gráfico de Calderón Quijano sobre la transformación del nombre Wallace en el sustantivo geográfico Belice (véase la figura 1): ${ }^{28}$ las grafías del nombre Wallace, luego topónimo Belice, se corresponden con documentos de archivo escritos en distintas épocas entre el siglo XVII y XIX; en ellos se aprecia la clara variación gráfica de nombre de persona a nombre de lugar.

Quebrado de Bercellón, derivado de Basil Jones, nombre y apellido del colono británico que arrendó o fue propietario de esa área de corte de madera en la sección norte de Cayo Ambergris. En todo caso, el sustantivo geográfico parece originarse en el modo en que los españoles pronunciaban Basil Jones y que varió hasta convertirse en Bercellon. Los documentos de EYCC lo mencionan con frecuencia bajo distintas modalidades: "surgidero de Bercellón”, “boca Bercellón”, fondeadero Bercellón. Algunos autores fechan en alrededor de 1790 el contrato de arrendamiento de Basil Jones en aquel lugar, ${ }^{29}$ pero el mapa de Juan José de León fechada en 1787 en el que figura Bercellón, ${ }^{30}$ así como la familiaridad de los documentos EYCC

${ }^{27}$ José Antonio Calderón Quijano, Historia de las fortificaciones en Nueva España, Madrid, Gobierno del Estado de Veracruz/Escuela de Estudios Hispano-Americanos, 1984, p. 33-34.

${ }^{28}$ Calderón Quijano, Historia de las fortificaciones..., p. 35.

${ }^{29}$ Glenn D. Godfrey, Ambergris Caye: Paradise with a Past, Belize, Cubola Productions, 1996, p. 6.

${ }^{30}$ Antochiw, Historia cartográfica..., lámina 117. 


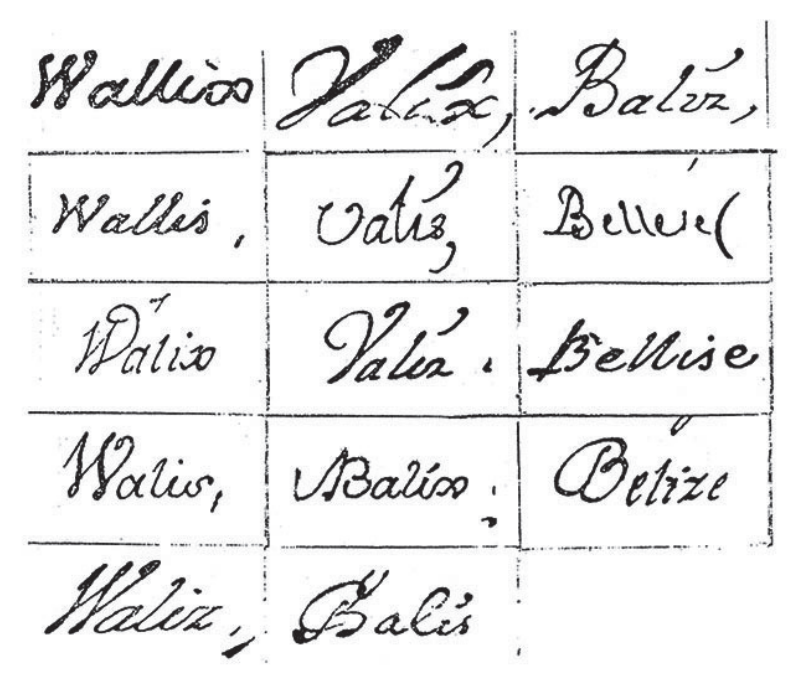

Figura 1. Las grafías del nombre Wallace, luego topónimo Belize, corresponden a documentos de archivo escritos en distintas épocas entre el siglo XVII y XIX. Imagen tomada de José Antonio Calderón Quijano, Belice 1633-1821.

Historia de los establecimientos del Río Valis hasta la independencia de Hispanoamérica, Sevilla, Universidad de Sevilla, Escuela de Estudios Hispano-Americanos, 1944, p. 35

con el "quebrado de Bercellón", en la barrera de arrecife, hacen suponer que el arriendo o propiedad de Basil Jones es de una fecha previa a 1790.

\section{Grupo 3. PeCuliaridades edÁficas y zoOgráficas: MANZANAS ARRUGADAS, CRUSTÁCEOS Y MOSQUITO}

Los documentos históricos (por ejemplo los de EYCC-1798) recogen una toponimia de ínsulas pobladas de arbustos de icaco (Cayo Icacos), de tierras anegadizas donde abundaba el árbol de majagua con su flor púrpura y madera buena para lanzas (Cayo Majagua), de breves páramos de piedra entre el mar y la costa donde proliferó el sisal, el tipo de agave con que se fabricaron las indispensables sogas que ataron las embarcaciones en muelles y radas, las mismas que fijaron las velas y aseguraron las mercancías en las bodegas de las naves (Cayo Sisal). Así como de isletas desiertas en las que se almacenaba y dejaba secar pastos y henos (Cayo Niazos). 
En una orilla marítima llena de vida vegetal y animal no sorprenden los topónimos asociados con la fauna: Isla Tortuga, Cayo Cangrejos, Cayo Culebra. Son nombres que remiten a la abundancia animal pululando entre más de dos centenares de pequeñas ínsulas de la costa Yucatán-Belice. Y claramente, Cayo Mosquitos evoca un reino de insectos, zumbidos y mordeduras. La toponimia costera avisa al navegante de las peculiaridades vegetales y animales del cayerío desperdigado en el Caribe.

Las manzanillas arrugadas que nadie conoce

Las manzanillas arrugadas que refiere Hernando Colón son una fruta no identificada en la actualidad. Las describe así: "una punta que [Cristóbal Colón] llamó Caxinas, porque había en ella muchos árboles que producían unas manzanillas algo arrugadas, con hueso esponjoso, buenas para comer, y especialmente cocidas, a las cuales llamaban Caxinas los indios de la Española". ${ }^{31}$ Cayo Cosina es un fitónimo, asociado a la flora de la isla, en este caso asociado a un fruto desconocido, y no es un pragmatónimo, derivado del hecho cotidiano de cocinar. Es de los pocos topónimos que podemos rastrear hasta su pasado prehispánico; Lorenzo Hermoso de Mendoza registró en 1758 el topónimo amerindio: "Cayo o Yslote que llaman de Quibilquel”. ${ }^{32}$ En el EYCC-1798 se puede localizar una reminiscencia de ese antiguo nombre de Cayo Cosina: "que fuesen a fondearse a Guibiquel o Cayo Cosina, en que hay buenos fondeaderos" (f. 49).

Los documentos legales de 1786 entre España y Gran Bretaña establecen que: "Será permitido a los ingleses ocupar la pequeña isla conocida con los nombres de Casina, St. George's Key, o Cayo Casina, en consideración a que parte de las costas que hacen frente a dicha isla consta ser notoriamente expuesta a enfermedades peligrosas". ${ }^{33}$ La grafía Casina puede ser verificada

${ }^{31}$ Citado por José Antonio Calderón Quijano, Belice 1633-1821. Historia de los establecimientos del río Valis hasta la independencia de Hispanoamérica, Sevilla, Universidad de Sevilla, Escuela de Estudios Hispanoamericanos, 1944, p. 57.

32 Transcrito por Calderón Quijano, Belice 1633-1821..., p. 439.

${ }^{33}$ Colección de los tratados de paz, alianza, comercio ajustados por la Corona de España con las potencias extranjeras desde el reynado del señor don Felipe Quinto hasta el presente, Madrid, Imprenta Real, 1801, t. III, p. 331. 
también en otro documento oficial de la época, en el registro anual de ese año que da cuenta del acuerdo entre España y Gran Bretaña. ${ }^{34}$

En resumen, Cayo Cosina, también Cayo Casina, actualmente es St. George Cay. El segundo sustantivo del nombre español de la ínsula deriva más del nombre de los frutos descritos por Hernando Colón, llamados "caxinas" y no identificados actualmente, ${ }^{35}$ que de la conjugación del verbo cocinar como algunos sugieren. ${ }^{36}$ Casina, con "a" y con "s", como lo registran los documentos legales de fines del siglo XVIII, es un topónimo que se desprende con mayor naturalidad de "caxina", el término usado por Hernando Colón. Ese antecedente también explicaría la persistencia de la "s" del topónimo en distintos mapas de fines del siglo XviII: "Caio Cosina";37 "C. Casina”; 38 "Key Kosina”,39 "C. Cozina". ${ }^{40}$

\section{Crustáceos}

El plural "Cangrejos" en los mapas del siglo XviII alternó con el singular del mismo sustantivo. El testimonio de una incursión española a la costa oriental de Yucatán en 1724 para desalojar británicos establecidos en el área, menciona a Cayo Cangrejo. ${ }^{41}$ La edición de 1865 del Derrotero de las islas Antillas y de las costas orientales registra que aún hay "cacimbas de buena agua" 42 en Cayo Corker, identificada por los españoles como Cayo de la Aguada, cerca del Cayo Cangrejo (en singular).

${ }^{34}$ The New Annual Register, or General Repository of History, Politics, and Literature for the Year 1787, London, 1788, p. 244.

${ }^{35}$ José María López Piñero, Francisco Hernández y José Pardo, Nuevos materiales y noticias sobre la historia de las plantas de la Nueva España, Valencia, Instituto de Estudios Documentales e Históricos sobre la Ciencia, 1994, p. 176.

${ }^{36}$ Alan K. Craig, Geography of Fishing in British Honduras and Adjacent Coastal Waters, Lousiana, Lousiana State Univesity Press, 1966, p. 36.

${ }^{37}$ Antochiw y Breton, Catálogo cartográfico de Belice..., p. 144.

${ }^{38}$ Antochiw, Historia cartográfica..., plano 117.

39 Odile Hofmann, British Honduras: The Invention of a Colonial Territory. Mapping and Spatial Knowledge in the 19th Century, Benque Viejo del Carmen (Belize)/Bondy (Francia), Cubola Books/Institut de Recherche pour le Dévelopment, 2014, p. 27.

${ }^{40}$ Antochiw y Breton, Catálogo cartográfico de Belice..., p. 149.

${ }^{41}$ Calderón Quijano, Belice 1633-1821..., p. 85 y 99.

${ }^{42}$ Derrotero de las islas Antillas y de las costas orientales de América, desde el río de las Amazonas hasta el cabo Hatteras, Bogotá, Dirección de Hidrografía, 1865, p. 392. 
El Derrotero de las islas Antillas informa del cambio geológico en los islotes próximos a Cangrejo: "según los trabajos hechos por los oficiales españoles, en 1794, la punta so de la isla Sabanilla llegaba hasta el sitio ocupado actualmente por el bajo de la Culebra". ${ }^{43}$ A fines del siglo xix la Sociedad de Geografía y Estadística de la República Mexicana recogió el topónimo también en singular. ${ }^{44}$ En el mapa de Juan José de León de 1787 se aprecia con nitidez el Canal de Cangrejos, en la proximidad de Cayo Cangrejos, en plural. ${ }^{45}$

En Cayo Cangrejos - también Cangrejo Cay- la abundancia de este crustáceo indica que Cayo Cangrejos sí es un zoónimo. Aunque sea tan pequeño este islote al sur de Ambergris, los itinerarios y las bitácoras de capitanes recuerdan el emplazamiento de Cayo Cangrejos por dos asuntos vitales de la navegación del siglo XVIII: el lugar está próximo a otro donde las naves pueden abastecerse de buena agua, Cayo Aguada (Cayo Corker), y casi frente a este cayo se ubica uno de los canales de entrada o salida de la barrera de arrecife que separa el mar abierto de la costa (Canal de Cangrejos). Nótese que Cangrejo Cay, para los ingleses, conservó el nombre en español del crustáceo que abunda en aquella zona.

\section{Mosquito}

Cayo Mosquito, isla diminuta como un mosquito, apenas figura en el cayerío frente al lindero sur del actual distrito de Corozal (Belice); es una isleta beliceña distinta a sus homónimas en Cuba, Nicaragua y Venezuela. No confundirla con Punta Mosquito en la isla de Holbox y tampoco con Cayo Mosquitos (en plural) de Guatemala. No forma parte de La Mosquitia, ese rosario de islotes de cabo Honduras al río Matina en Costa Rica.

Aunque repetido en la cartografía caribeña, este Cayo Mosquito de las costas beliceñas tiene la singularidad del poco calado de sus aguas. En el EYCC-1798 se puede leer el pasaje siguiente: "hice venir a los prácticos y en presencia de sus comandantes les pregunté si el bergantín podría seguir hasta Cayo Mosquito sin arriesgar el buque. Me contestaron que sí podía, pero desde ese paraje no podría continuar" (f. 4). En efecto, un informe posterior

${ }^{43}$ Derrotero de las islas Antillas..., p. 393.

${ }^{44}$ Boletín de la Sociedad Mexicana de Geografía y Estadística, Sociedad Mexicana de Geografía y Estadística, México, 1888, p. 30.

${ }^{45}$ Antochiw, Historia cartográfica..., plano 117. 
señala la necesidad de llevar embarcaciones pequeñas "cuya cala no pasaría de tres pies y medio de agua a fin de que pudieran entrar por Boca Chica, $\mathrm{u}$ otra [salida] inmediata de las que tiene la cadena [del arrecife], y pasar entre Cayo Cangrejo y Cayo Mosquito hasta la batería de Chac, inmediata a Bacalar" (f. 244). Además del poco calado, en la proximidad de Cayo Mosquito las naves pequeñas debían vigilar el peso que transportaban (cañones y bastimento), como se deduce de la siguiente observación: "me parece muy bien la determinación de vuestra merced de embarcar en los buques de menos calado algunos de los víveres que alijaron los barcos mayores, que no pudieron entrar; pero vea vuestra merced que esto no sea demasiado con presencia de la poca agua que hay en los cayos Sabana y Mosquitos" (f. 514).

\section{GRUPO 4. TRADUCCIONES ENREDADAS: de Chapel Key a Cayo Chiapa}

Cayo Chiapa, también en plural: Cayo Chapas y Cayo Chiapas, y a veces Cay Chapelle y asimismo Capel $\mathrm{K}$, actualmente se llama Cay Chapel. Una rápida revisión a los mapas históricos permite entender la confusa escritura del topónimo: en el mapa inglés de 1777, el de Thomas Jeffrys, figura claramente el nombre Chapel Key; ${ }^{46}$ en un mapa francés que señala la parte de Yucatán cedida por los españoles a los ingleses en los tratados de 1783 y 1786, se lee "Cay Chapelle"; ${ }^{47}$ en un mapa español de 1787, el de Juan José de León, se aprecia la abreviatura: "C. Chiapa”. Las tres variantes para una pequeña isla.

Para los mapas españoles pudo llamarse Cayo de la Capilla - un rústico adoratorio prehispánico debió existir en el lugar-. Pero en EYCC-1798 figura como Cayo Chiapa: "El 9 no nos dio el viento y el 10 nos franqueamos del bajo de Cayo Chiapa poniéndonos todos sobre Cayo Largo" (f. 30).

Un mapa inglés de 1777, el de Jeffrys, anota "Chapel Key" y señala la existencia de un canal, un paso entre el arrecife del lugar. Para la navegación costera estas observaciones eran importantes porque indicaban los lugares en los que se podía entrar o salir del mar interior al mar abierto, al otro lado de la barrera de arrecife. El "canal de Cayo Chiapa para balandros", como lo

${ }^{46}$ Antochiw, Historia cartográfica..., p. 203.

${ }^{47}$ Hoffmann, British Honduras..., p. 27. 
especifica un mapa de $1814,{ }^{48}$ era muy usado por embarcaciones pequeñas de la región. Por los itinerarios marítimos de Celarain ${ }^{49}$ y Godoy ${ }^{50}$ sabemos que los navegantes locales lo denominaron "quebrado de Cayo Chapas".

Al final, la confusión reinó en la escritura del topónimo, lo que pudo ser una sencilla traducción, "Cayo de la Capilla”, derivó en el confuso "Cayo Chiapa”, como si la costa chiapaneca no se extendiera en otro océano.

Grupo 5. Pasado ÉtNico:

Isla Contoy, Estero de Chac y Cayo Negro

Cabo Catoche es un topónimo maya referido con frecuencia en las crónicas de los primeros exploradores españoles de la costa de Yucatán. Cuenta Bernal Díaz del Castillo que los habitantes del lugar donde habían llegado "estaban diciendo en su lengua: cones cotoche, cones cotoche, que quiere decir: andad acá, a mis casas, y por esta causa pusimos por nombre a aquella tierra Punta de Cotoche". ${ }^{51}$

\section{Isla Contoy}

En cambio, Contoy (isla) y Chac (estero) son topónimos con un significado menos documentado. En los mapas históricos, isla Contoy figura también como El Contoy y Loggerhead Key. Actualmente es el Parque Nacional Isla Contoy.

El topónimo de origen maya no siempre prevaleció: Contoy quizá significó para los mayas un lugar de abrigo para sus embarcaciones o un sitio con pelícanos. Los británicos vieron en la misma isla una gran cantidad de tortugas y desde los primeros años del siglo Xvir el lugar figura en sus mapas como Loggerhead Key. Diego López Cogolludo hace referencia a "la Isla de Contoy" cuando escribe su Historia de Yucatán en 1655. Pero la

${ }^{48}$ Antochiw y Breton, Catálogo cartográfico de Belice..., p. 100.

${ }^{49}$ Juan Pablo Celarain, Itinerarios y leguarios que proceden de Mérida, capital del estado de Yucatán a las vigías de su parte litoral, Mérida, 1851, p. 7.

${ }^{50}$ José J. Álvarez y Rafael Durán, Itinerarios y derroteros de la República Mexicana, México, Imprenta de José A. Godoy, 1856, p. p. 184.

${ }^{51}$ Bernal Díaz del Castillo, Historia verdadera de la conquista de la Nueva España, 2 t., México, Porrúa, 1977, t. I, p. 46. 
descripción extensa y temprana que encontramos del lugar es del viajero inglés Dampier, quien la visitó en $1675 .{ }^{52} \mathrm{El}$ plano histórico más detallado de Isla Contoy fue levantado por uno de los miembros de la expedición Yucateca a Cayo Cocina de 1798, Antonio Romero, segundo piloto de la fragata $O .^{53}$

Un breve análisis de los mapas españoles e ingleses del siglo XVIII muestra el registro de "Isla Contoy" para los primeros y "Loggerhead Key" para los segundos. A principios del siglo XIX, tanto los libros marítimos como las enciclopedias y los diccionarios geográficos se ocupan de la equivalencia. "Is called by the Spaniards El Contoy [...] our sailor name the first Logerhead Key, and the second Key Mahair." ${ }^{4}$ Una enciclopedia de Londres: "Loggerhead Key, or el Contoy". ${ }^{55}$ Un diccionario geográfico: "Loggerhead Key, or El Contoy". ${ }^{56}$

El mapa de 1734 del primer cartógrafo de la península de Yucatán, Joseph De Guelle, registra con claridad "Contoy". ${ }^{57}$ La descripción de Juan de Villajuana sobre la provincia de Yucatán, escrita en 1751, dice: "La Isla de Mujeres, el Contoy y la Blanquilla están al fin de Cabo Catoche". ${ }^{58}$ Los prácticos marítimos de Campeche (navegantes con conocimiento de matemáticas y experiencia en el uso de instrumentos de navegación de la época) dibujaron en 1761 su propio mapa y registran "Contoy". ${ }^{59} \mathrm{El}$ mapa de 1776 de Miguel Alderete registra igualmente "Contoy". ${ }^{60}$ Otro mapa español de 1789 recoge "i de Contoy". ${ }^{61}$ Y el mejor mapa español del área de fines del siglo XVIII, el de Juan José de León de 1798, recoge en sus notas: "G. Canal del Contoy, Ysla Blanquilla". ${ }^{62}$

52 Dampier, Dos viajes a Campeche..., p. 53.

${ }^{53}$ Ese plano se reproduce en Antochiw, Historia cartográfica..., plano 110.

${ }^{54}$ Lawrence Furlong, The American Coast Pilot: Containing the Courses and Distances between the Principal Harbors, Capes and Headlands, Newburyport (Massachusetts), Printed by Edmund M. Blunt, 1806, p. 259.

${ }^{55}$ Abraham Ress, Ciclopedia; or Universal Diccionary of Arts, Sciences \& Literature, London, Longman, Hurst, Rees, Orme \& Brown, 1824, v. 4, p. 906.

${ }^{56}$ Joseph Emerson Worcester, A Geographical Dictionary, or Universal Gazetteer, 2 t., Salem, Cummings \& Hilliard, 1817, p. 417.

${ }^{57}$ Antochiw, Historia cartográfica..., plano 5. También en Antochiw, Historia cartográfica..., lámina XXIX.

${ }^{58}$ Expediente transcrito en Calderón, Belice 1633-1821..., p. 163.

${ }^{59}$ Antochiw, Historia cartográfica..., p. 210.

${ }^{60}$ Antochiw, Historia cartográfica..., p. 112.

${ }^{61}$ Antochiw, Historia cartográfica..., p. 279.

${ }^{62}$ Antochiw, Historia cartográfica..., lámina XXXII. 
El cartógrafo inglés Thomas Jeffreys registra "Loggerhead Key" en sus mapas de 1775 y $1777 .{ }^{63} \mathrm{~A}$ finales del siglo xvin el mapa de Robert y William Hodgson, fechado en 1782, anota con letra grande y visible "Loggerhead Key". ${ }^{64}$

La siguiente descripción es del viajero inglés William Dampier y se corresponde con el año de 1675:

Alrededor de tres leguas de cabo Catoche, y justo frente a él, hay una pequeña isla llamada cayo Loggerhead, probablemente porque la visita frecuentemente una especie de tortuga llamada así; cerca de esta isla encontramos siempre un gran rizado de olas, que los hombres del mar llaman siempre los rip-raps. Este cabo, aunque parece siempre formar parte de tierra firme, está sin embargo dividido de ella por una pequeña ensenada, apenas lo bastante ancha para que pase por ella una canoa, que es lo que hace de él una isla [...] El cabo es tierra muy baja cerca del mar, pero algo más alta mientras se aleja uno de la costa. Todo él está tupido de árboles de diversas suertes, especialmente palo de tinte y por lo tanto antiguamente lo frecuentaban mucho más los hombres de Jamaica, quienes venían hasta aquí en balandras para cargarlas de ellos, hasta que todos los árboles de palo de tinte cerca del mar fueron cortados; ahora está abandonado por completo, ya que acarrearlos hasta la orilla exige más trabajo que talar, cortar y astillar. ${ }^{65}$

\section{Estero de Chac}

Estero de Chac es otro topónimo que evidencia su pasado maya. En los mapas históricos también se registra como Xiac, Chak Creek, White Water. De los posibles nombres del pasado, el agua prevalece como elemento central del topónimo: Chaac es el dios maya de la lluvia. ${ }^{66}$ Sin embargo, el nombre de este afluente del río Hondo pasó de tierra firme al cuerpo de agua. Por el análisis de mapas, creemos que el estero de Chac tomó el nombre del paraje sobre el que pasa el afluente: el mismo paraje que después encontraremos referido como Batería de Chac, Vigía de Chac.

Para los británicos el afluente fue Chak Creek o White Water. En un plano de Bacalar y su salida al mar, fechado en 1726 por el cartógrafo Alejandro

${ }^{63}$ Antochiw, Historia cartográfica..., p. 201 y 203, fig. 5 y 6.

${ }^{64}$ Antochiw, Historia cartográfica..., p. 204.

${ }^{65}$ Dampier, Dos viajes a Campeche..., p. 53.

${ }^{66}$ Yucatán en el tiempo. Enciclopedia alfabética, 6 t., México, Inversiones Cares, 1998, t. II, p. 199. 
Joseph De Guelle, figura con nitidez el nombre de "Xiac" sobre una porción de tierra aislada por dos afluentes del río Hondo. ${ }^{67}$ Otro plano de 1783 que cartografía los tres ríos del área, incluyendo al río Hondo, no identifica a Chac; pero coloca el nombre de "Canxax" al cuerpo de agua que está antes de la laguna de Bacalar y al extremo del estero de Chac. ${ }^{68}$ Deducimos que Xiac, una aldea abandonada probablemente desde el siglo XVI, dio el nombre al afluente en algún momento del siglo XVII. Al cambio de siglo, los planos conocidos registran entre 1858 y 1886: "Chack Creek"; ${ }^{69}$ "Chac Creek";70 "El Chac". 71

Cayo Negro

Cayo Negro es actualmente Blackdore Caye. No encontramos evidencia documental en el siglo XviI que asocie a Cayo Negro con el anterior nombre de Cayo Sumba, como sugiere una moderna guía turística. ${ }^{72}$ Un mapa de 1783 señala a Sumba ligeramente al norte de Punta Piedras: ${ }^{73}$ Sumba y Cayo Negro son isletas diferentes. Cayo Negro figura con ese nombre español al menos desde 1776, como se puede comprobar en los mapas históricos. ${ }^{74}$

En el siglo XviII, Andrés Manuel del Río utilizó en sus obras científicas un nuevo vocabulario proveniente de la nomenclatura química: lo que llamamos óxido, Andrés Manuel del Río denominó cayo. En ese sentido, el término cayo negro refiere al color azulado en la gama de colores que se forman sobre la superficie de metales por oxidación. Azulado "es un negro mezclado de azul, y constituye el paso de uno a otro: el cayo negro de cobalto terroso" ${ }^{75}$

${ }^{67}$ Alejandro Joseph De Guelle, El primer cartógrafo de la península de Yucatán, Campeche, Centro inah Campeche/Gobierno del Estado de Campeche, Secretaría de la Cultura, Instituto de Cultura del Estado de Campeche/Universidad de Campeche, 2004, p. 76.

${ }^{68}$ Hoffmann, British Honduras..., p. 23.

${ }^{69}$ Hoffmann, British Honduras..., p. 49, 51 y 57.

${ }^{70}$ Antochiw y Breton, Catálogo cartográfico de Belice..., lámina LXVII.

${ }^{71}$ Hoffmann, British Honduras..., p. 59.

${ }^{72}$ Richard L. Woods, Tomlison Reid y Alastair M. Reid, The Field Guide to Ambergris Caye, C. A., Including other Atolls, Belize, Woods, Reid \& Reid, 1988, p. 16.

${ }^{73}$ Hoffmann, British Honduras..., p. 23.

${ }^{74}$ Antochiw y Breton, Catálogo cartográfico de Belice..., p. 81.

75 Andrés Manuel del Río, Elementos de orictognosia, o del conocimiento de los fósiles, dispuestos, según los principios de A. G. Wérner, para el uso del Real Seminario de Minería de México, México, Imprenta de Mariano Joseph de Zúñiga y Ontiveros, 1795, p. XIV. 
La descripción del "azulado" (negro mezclado de azul) bien podría ser el color del mar en la proximidad de Cayo Negro visto desde las alturas y en cierto ángulo en un atardecer nublado: para el filólogo es tentadora la posibilidad de asociar la nomenclatura de las propiedades minerales usada por el catedrático Andrés Manuel del Río en el siglo XVIII (cayo negro: azulado) con la ínsula homónima.

Pero en el caso del Caribe, el origen arahuaco de la palabra cayo descarta la nomenclatura usada por Andrés Manuel del Río en el siglo XVIII. Así, menos mineral y más etnográfico, Cayo Negro revela en el adjetivo un pasado africano que se evidencia al cotejar el nombre completo de la isla en un compendio geográfico de Guatemala: Cayo Negro Head. ${ }^{76}$

\section{Grupo 6. NOMbRes Llanos:}

Boca Chica, Punta Calentura

Lo opuesto a boca grande, Boca Chica. En los mapas históricos, ese paso del mar Caribe a la bahía de Chetumal quedó registrado también como Boca de Bacalar Chico, Sombrerete, Zaragoza, Río Sangre. El pragmatismo del vocabulario marítimo de mediados del siglo xvin se impuso en el nombre de este estrecho canal artificial prehispánico, después punto fronterizo entre Xcalak (México) y Ambergris (Belice). La boca o entrada a una bahía suele ser ancha, ${ }^{77}$ pero en este caso se trata de una entrada angosta, una boca chica, desde "el mar Caribe a la bahía de Chetumal" en el camino náutico a Bacalar. El cartógrafo Alejandro Joseph De Guelle exploró Bacalar y sus alrededores en 1726 y recogió el nombre de "Toxecacao" como el lugar que hoy se corresponde con Boca de Bacalar Chico. ${ }^{78}$

El topónimo de Boca Chico es de mediados del siglo XviII: ese sustantivo geográfico con su respectivo adjetivo puede ser producto tanto del pragmatismo de la lexicografía náutica como de la necesidad de dar nombre inocuo a un lugar de referencia en los reconocimientos y concesiones

${ }^{76}$ Diccionario geográfico de Guatemala, 2 t., Guatemala, Tipografía Nacional, 1961, p. 43 y 78 , t. I.

${ }_{77}$ Martín Fernández de Navarrete, Diccionario marítimo español, que además de las definiciones de las voces con sus equivalentes en francés, inglés e italiano, contiene tres vocabularios de estos idiomas con las correspondencias castellanas, Madrid, Imprenta Real, 1831, p. 72.

${ }^{78}$ Michel Antochiw, Artillería y fortificaciones en la península de Yucatán, siglo XVIII, Campeche, Gobierno del Estado de Campeche, 2004, p. 87. 
territoriales entre españoles y británicos sobre la costa oriental de Yucatán en la segunda mitad del siglo XVIII.

Fiebre en la costa

Punta Calentura, también Punta de Calenturas. Los mapas del área fechados en la década de 1780 registran la expresión Punta de Calenturas: suponemos que este sustantivo geográfico es un pragmatónimo. La fiebre y la calentura fueron un hecho cotidiano para quienes habitaban temporal o permanentemente un selvático sitio costero a la entrada de la bahía de Chetumal a fines del siglo XVIII. Ochenta años después, a mediados del siglo XIX, el pragmatónimo perdió la conjunción y el plural de su segundo sustantivo: tanto mapas e informes gubernamentales registran desde la década de 1840 el nombre de Punta Calentura.

En el plano de los tres ríos de $1783,{ }^{79}$ en el plano de Juan José de León de $1787^{80}$ y en un plano francés de fines del siglo XVIII, ${ }^{81}$ se puede localizar el "registro Punta de Calenturas". En los dos primeros planos la ubicación es la que hoy conocemos en el territorio mexicano. Pero el tercer plano se equivoca al situarla en la orilla opuesta, en Punta Piedras (Rocky Point), el lado beliceño. Sin duda, lo que sí estuvo en ambas fronteras y diezmó tanto a colonos británicos como españoles fue la fiebre del trópico, la calentura de la enfermedad en costas e islas del Caribe: la malaria.

\section{NOTA FINAL}

El cayerío menor de la costa Yucatán-Belice está a la espera de un estudio histórico de los topónimos de islotes, cayos, quebrados y bajos. El recorrido por la toponimia de algunos sitios del área abre una ventana al significado cultural de ciertas maderas para fabricación de armas y utensilios, a la abundante fauna marítima del laberinto insular caribeño, a la forma de islas y puntas de tierra, a parajes costeros y a canales entre el arrecife mesoamericano que permitían pasar del furioso mar abierto al oleaje manso

\footnotetext{
${ }^{79}$ Hoffman, British Honduras..., p. 23.

${ }^{80}$ Antochiw, Historia cartográfica..., mapa 117.

${ }^{81}$ Antochiw y Breton, Catálogo cartográfico de Belice..., p. 97-98.
} 
del mar interior, protegido precisamente por la gran barrera de arrecife, la segunda más grande del mundo.

La toponimia como alerta de naufragio tiene en Alacranes y Chinchorro dos ejemplos. Los mapas históricos cuentan que el sustantivo geográfico de Alacranes no es el de un zoónimo, sino una alegoría del infortunio en alta mar. Por su parte, Chinchorro asocia cuatro nombres más para un mismo sitio: como testimonio de navegación frecuente por el área o como muestra de escuelas cartográficas distintas. De los cinco topónimos para el mismo sitio, Quitasueño es el nombre que posiblemente mejor funcionó como advertencia de naufragio en una época donde los faros modernos eran inexistentes en la costa del Caribe mexicano.

En una difusa frontera colonial española e inglesa del siglo XVII y XVIII -próxima al arrecife mesoamericano, a la bahía de Términos y a la bahía de Chetumal-fue común la toponimia originada en equívocos lingüísticos: en palabras que transitaron del inglés al español o viceversa. El colono inglés Basil Jones se convirtió en el sustantivo geográfico Bercellón (quebrado de) y el colono inglés Tom Laco en el sustantivo geográfico Tamalcab (isla, en la bahía de Chetumal). Ni Bercellón tiene origen en los corsarios franceses ni Tamalcab es voz maya. Equívocos en la pronunciación y en la escritura, como el de la isla Trs (abreviatura española de la época para “Términos") convertida por los ingleses en "Isla de Tris", son también el origen de los topónimos Bercellón y Tamalcab.

El registro de flora y fauna que se deduce de los topónimos del área, frutas desconocidas, crustáceos y mosquitos, ofrece un indicador de las transformaciones de la naturaleza en la costa caribeña. Complementado con los testimonios de viajeros y navegantes al Caribe en los siglos xviI y XVIII, el cuadro de la erosión de costas y depredación vegetal y animal queda más preciso. Lo que hoy son pequeñas islas erosionadas, con vegetación joven o sin ella, tuvieron un pasado arbóreo que hoy cuesta trabajo imaginar. Como relata el viajero Dampier, los árboles tintóreos fueron arrasados primero en las islas y en la costa por la facilidad y cercanía para transportarlos a las embarcaciones.

Los caminos confusos por los que son empujados algunos topónimos se aprecian en el caso de Cay Chapel. Lo que pudo ser llanamente Cayo de la Capilla en el mar Caribe, se registró como Cayo Chiapa, como si la costa de Chiapas no fuera orilla de otro océano. Por otro lado, los topónimos de Isla Negra y Cabo Catoche son huella etnográfica de dos grupos humanos marginados en el Caribe colonial: mayas y africanos. Tan ciertos estos 
topónimos étnicos como los sustantivos geográficos en el último grupo. Los topónimos nacidos del pragmatismo, de la enfermedad, en lo cotidiano de la navegación de cabotaje en la región, como Boca Chica (canal de Boca Chica, donde las embarcaciones pequeñas pasan) y Calenturas (Punta de Calenturas, donde el piquete de los abundantes mosquitos puede provocar las fiebres de la temible malaria).

\section{BIBLIOGRAFÍA}

Álvarez, José J., y Rafael Durán, Itinerarios y derroteros de la República Mexicana, México, Imprenta de José A. Godoy, 1856.

Antochiw, Michel, Historia cartográfica de la península de Yucatán, México, Instituto Politécnico Nacional, Centro de Investigación y Estudios Avanzados/Gobierno del Estado de Campeche/Grupo Tribasa, 1994.

Artillería y fortificaciones en la península de Yucatán, siglo XVIII, Campeche, Gobierno del Estado de Campeche, 2004.

Antochiw, Michel, y Alain Breton, Catálogo cartográfico de Belice (1511-1880). Cartographic Catalog of Belize (1511-1880), San José (Costa Rica)/México, Bureau Régional de Coopération en Amérique Centrale/Centre d'Études Mexicaines et Centraméricaines, 1992.

Boletín de la Sociedad Mexicana de Geografía y Estadística, Sociedad Mexicana de Geografía y Estadística, México, 1888.

Calderón Quijano, José Antonio, Belice 1633-1821. Historia de los establecimientos del río Valis hasta la independencia de Hispanoamérica, Sevilla, Universidad de Sevilla, Escuela de Estudios Hispano-Americanos, 1944.

Historia de las fortificaciones en Nueva España, Madrid, Gobierno del Estado de Veracruz/Escuela de Estudios Hispano-Americanos, 1984.

Carneyro, Antonio de Maris, y Antonio de Poza, Hydrografia la más curiosa que hasta hoy a luz a salido, recopilada de varios y escogidos autores de la navegación, Provincia de Guipúzcoa, 1675.

Celarain, Juan Pablo, Itinerarios y leguarios que proceden de Mérida, capital del estado de Yucatán a las vigías de su parte litoral, Mérida, 1851.

Colección de los tratados de paz, alianza, comercio ajustados por la Corona de España con las potencias extranjeras desde el reynado del señor don Felipe Quinto hasta el presente, Madrid, Imprenta Real, 1801, t. III.

Craig, Alan K., Geography of Fishing in British Honduras and Adjacent Coastal Waters, Lousiana, Lousiana State University Press, 1966. 
DAmpier, William, Dos viajes a Campeche. Con el facsímil de la edición inglesa de 1705, México, Miguel Ángel Porrúa, 2004.

Darwin, Charles, The Works of Charles Darwin. Volume 7. The Geology of the Voyage of the H. M. S. Beagle. Part I: Structure and Distribution of Coral Reefs, New York, New York University Press, 1986.

De GuELle, Alejandro Joseph, El primer cartógrafo de la península de Yucatán, Campeche, Centro inaн Campeche/Gobierno del Estado de Campeche, Secretaría de la Cultura, Instituto de Cultura del Estado de Campeche/Universidad de Campeche, 2004.

Derrotero de las islas antiguas, de las costas de tierra firme y de las del seno megicano, corregido y aumentado con un apéndice sobre las corrientes del océano Atlántico, Bogotá, Dirección de Hidrografía, 1826.

Derrotero de las islas Antillas y de las costas orientales de América, desde el río de las Amazonas hasta el cabo Hatteras, Bogotá, Dirección de Hidrografía, 1865.

Díaz del Castillo, Bernal, Historia verdadera de la conquista de la Nueva España, 2 t., México, Porrúa, 1977.

Diccionario geográfico de Guatemala, 2 t., Guatemala, Tipografía Nacional, 1961.

EYCC-1798 (1798), Expedición Yucateca a Cayo Cocina, 1798. Documentos españoles sobre la batalla de Cayo Cocina de 1798, 1100 fojas seleccionadas del Archivo de Indias (inédito).

Fernández de Navarrete, Martín, Diccionario marítimo español, que además de las definiciones de las voces con sus equivalentes en francés, inglés e italiano, contiene tres vocabularios de estos idiomas con las correspondencias castellanas, Madrid, Imprenta Real, 1831.

FERnÁndez de Oviedo, Gonzalo, Historia general y natural de las Indias, 5 v., Madrid, Atlas, 1992 (Biblioteca de Autores Españoles, 118).

Ferrer Muñoz, Manuel, "Notas sueltas sobre presencia de canarios en Yucatán (siglos XVIII y XIX)”, Anuario de Estudios Atlánticos, 2002, p. 121-132.

Furlong, Lawrence, The American Coast Pilot: Containing the Courses and Distances between the Principal Harbors, Capes and Headlands, Newburyport (Massachusetts), Printed by Edmund M. Blunt, 1806.

Godfrey, Glenn D., Ambergris Caye: Paradise with a Past, Belize, Cubola Productions, 1996.

GonzÁlez Aguiar, María Isabel, Análisis y descripción onomasiológica del léxico canario, Santa Cruz de Tenerife, Universidad de la Laguna, 1999.

Hof f mann, Odile, British Honduras: The Invention of a Colonial Territory. Mapping and Spatial Knowledge in the 19th Century, Belize/Bondy (Francia), Cubola Books/Institut de Recherche pour le Dévelopment, 2014. 
López de Cogolludo, Diego, Historia de Yucatán, 3 v., Campeche, H. Ayuntamiento de Campeche, 1995-1997.

López Piñero, José María, Francisco Hernández y José Pardo Tomás, Nuevos materiales y noticias sobre la historia de las plantas de la Nueva España, Valencia, Instituto de Estudios Documentales e Históricos sobre la Ciencia, 1994.

Memoria sobre las observaciones astronómicas hechas por los navegantes españoles en distintos lugares del globo, Madrid, Imprenta Real, 1889, t. I.

Memorias geográficas, históricas, económicas y estadísticas de la isla de Puerto Rico, San Juan, Oficina del Gobierno, 1832, t. 3.

Pérez Aguilar, Raúl, Lexicografía en la frontera México-Belice. Canarismos e indigenismos en la frontera mexicana con Belice, Madrid, Editorial Académica Española, 2017.

QueStell Rodríguez, Eduardo, La central "Constancia” y el desarrollo azucarero de Toa Baja, San Juan (Puerto Rico), Servicio de Consultoría Arqueológica, 2010. Ress, Abraham, Ciclopedia; or Universal Diccionary of Arts, Sciences \& Literature, London, Longman, Hurst, Rees, Orme \& Brown, 1824, v. 4.

Río, Andrés Manuel del, Elementos de orictognosia, o del conocimiento de los fósiles, dispuestos, según los principios de A. G. Wérner, para el uso del Real Seminario de Minería de México, México, Imprenta de Mariano Joseph de Zúñiga y Ontiveros, 1795.

The New Annual Register, or General Repository of History, Politics, and Literature for the Year 1787, London, 1788.

Woods, Richard L., Tomlison Reid y Alastair M. Reid, The Field Guide to Ambergris Caye, C. A., Including other Atolls, Belize, Woods, Reid \& Reid, 1988.

WorCester, Joseph Emerson, A Geographical Dictionary, or Universal Gazetteer, 2 t., Salem, Cummings \& Hilliard, 1817.

Yucatán en el tiempo. Enciclopedia alfabética, 6 t., México, Inversiones Cares, 1998. 

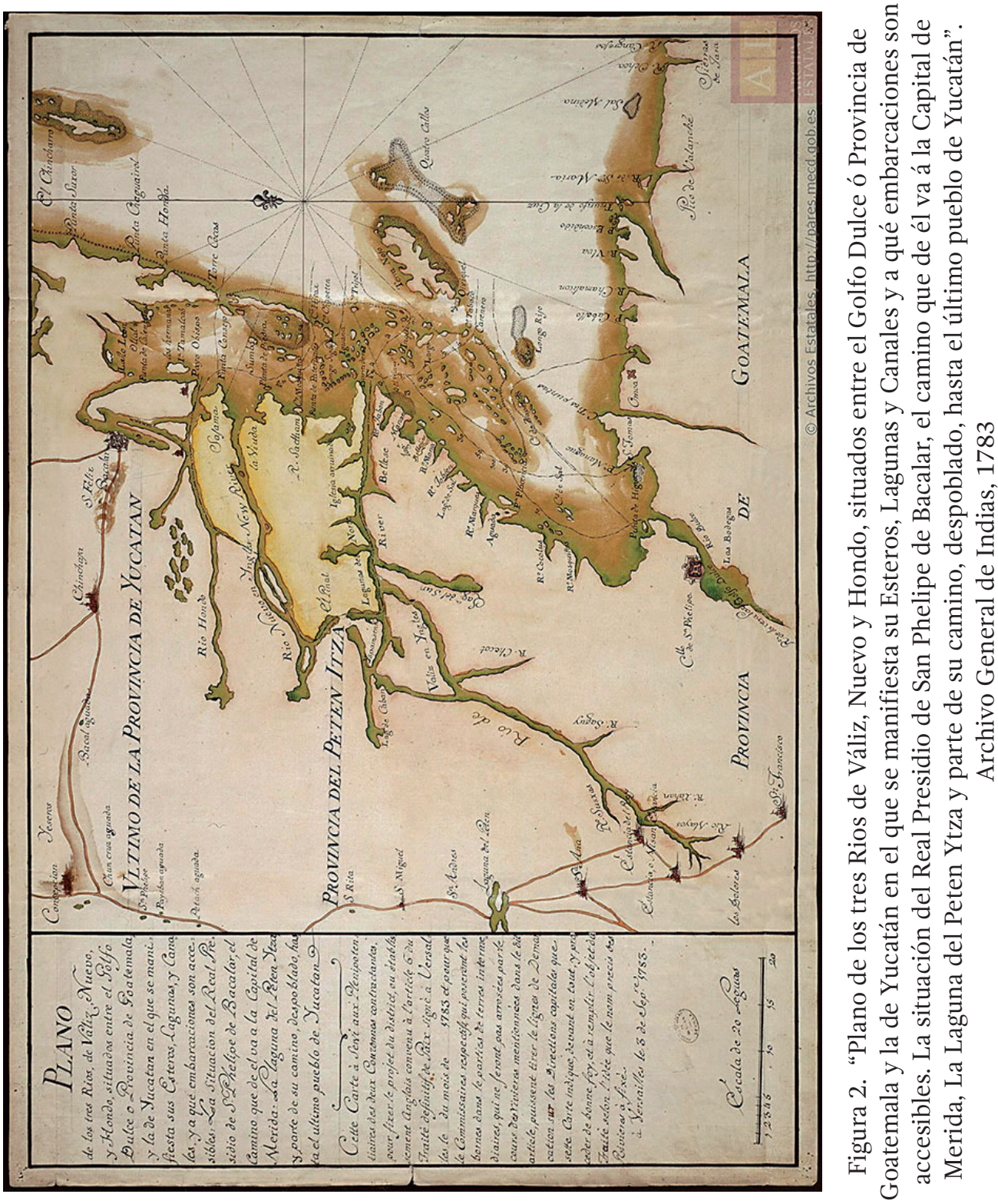